\title{
Penanda Fatis dalam Bahasa Jawa yang Digunakan oleh Masyarakat Madura di Jember
}

\author{
Siti Yuliana, Akhmad Sofyan, Asrumi \\ sitiyuliana91@gmail.com
}

Diterima 11 Mei 2015/Disetujui 20 Juni 2015

\begin{abstract}
This article discusses is phatic marker in Javaneese language (BJ) that is used by Madureese society in Jember. Madura speaker when talking on BJ, then the marker is a marker spoken phatic is phatic BM. In terms of speakers, in the form of BJ phatic marker used by the Madurese community in Jember assortment as well as in terms of the use and distribution also varies. There are three steps that are used in this research, which are 1) data collection steps, 2) data analysis step, 3) presentation of the data analysis. Result step the method that is used in the data collection step is simak method. The second step is data analysis step, which are agih method. The third step is the presentation of the data analysis result is informal method. Based on research results, he form of phatic communion in BJDJ are in the form of 1) particles 2) phatic words, 3) word repetitions, and 4) the use of affixes. Phatic communion is particles, which are jhâ', kan, ko dan ra, yâ, lâ, pas, ta, dhing, ki, lah, and mbok. Phatic communion is phatic words, which are sènga', ma', adâ', bâh, mara, jeneng, mboh, wés, and mayo'. Phatic communion is word repetitions, which are cén, ndak, jal, mboh, yo, and iku. Phatic communion is use of affixes, which are $-a n$ and $-e n$.
\end{abstract}

Key words: Phatic marker, particles, phatic words, word repetitions, the use of affixes

\section{Pendahuluan}

Di Jember, interaksi antara penutur Madura dan Jawa melahirkan sebuah variasi bahasa Jawa yang mempunyai perbedaan dalam struktur dengan bahasa Jawa (BJ)baku. Variasi BJ biasanya digunakan oleh penutur Madura di kota dan pinggiran kota ketika mereka berkomunikasi dengan penutur Jawa, tetapi ketika berkomunikasi dengan sesama penutur Madura mereka tetap menggunakan bahasa Madura (BM). BJ lisan yang mereka gunakan berbeda dengan BJ baku karena pengaruh dari bahasa pertama (BM). Berikut contoh bahasa yang digunakan dalam percakapan sehari-hari antara etnis Jawa (EJ) dan etnik Madura (EM).

(EJ) : "Kate nang endi, Mas"?

(EM) :"Gak onok, iki ku-mlaku”.

Jawaban Gak onok, iki ku-mlaku merupakan usaha menggunakan BJ yang dipengaruhi bahasa Madura (Sofyan dan Wibisono, 2001).

Berbicara tentang bahasa lisan, ada hal menarik dalam bahasa lisan pada variasi BJ di Jember. Hal tersebut ialah penanda fatis yang ada dalam tuturan masyarakat Jember. Penanda fatis merupakan ciri ragam lisan yang bertugas untuk memulai, mempertahankan, mengukuhkan atau mengakhiri pembicaraan antara penutur dan lawan tutur (Kridalaksana, 2005:116). Sebagian besar kategori fatis merupakan ciri ragam bahasa lisan (nonstandar) sehingga kebanyakan kalimat-kalimat nonstandar banyak mengandung unsur-unsur daerah atau dialek regional (Kridalaksana, 2005:116). Misalnya pada tuturan berikut. 
1) Menurutmu apa aku pantas memakai baju ini?

2) Kamu pantas kok memakai baju itu, kelihatan cantik.

3) Ah, biasa saja sih menurutku.

4) Kamu kelihatan cantik kok soalnya kamu memakai baju berwarna biru.

5) Ya, kan warna biru adalah warna kesukaanku.

Dari contoh tuturan di atas, ada kata-kata yang sulit diidentifikasi fungsinya dalam kalimat, misalnya kok, ah, sih, ya, dan kan yang juga dijumpai dalam percakapan sehari-hari. Jika kata-kata tersebut dimasukkan dalam kalimat kita akan sedikit mengalami kesulitan untuk menentukan maknanya secara leksikal. Kata-kata tersebut dalam istilah kebahasaan disebut penanda fatis.

Dalam tuturan, seseorang sering menggunakan ungkapan fatis untuk memulai, mempertahankan, mengukuhkan atau mengakhiri pembicaraan antara penutur dan lawan tutur agar tuturannya menjadi lebih jelas. Ungkapan fatis biasanya diucapkan secara spontan oleh penutur sehingga ungkapan fatis yang keluar dalam tuturan tersebut akan mewakili siapa yang menuturkannya. Ungakapan fatis tersebut bisa menunjukkan dari mana penutur itu berasal. Misalnya dalam tuturan berikut: Lho mak ngunu? Ojo dicampuri bawang 'lho kok begitu jangan dicampuri bawang'. Penanda fatis tho mak merupakan penanda fatis gabungan dari BJ dan BM. Kata tho merupakan penanda fatis yang berasal dari BJ dan kata mak berasal dari BM. Kedua penanda fatis tersebut sering digunakan dalam satu tuturan sehingga menimbulkan sifat keunikan tersendiri dari penanda fatis BJ yang digunakan oleh masyarakat Madura di Jember. Oleh karena itu, dilihat dari segi penuturnya bentuk penanda fatis dalam BJ yang digunakan oleh masyarakat Madura di Jember bervariasi. Kemudian, dari segi pemakaian dan distribusinya juga bervariasi. Hal tersebut yang menjadi alasan pemilihan tema penelitian mengenai penanda fatis dalam BJ yang digunakan oleh masyarakat Madura di Jember. Penelitian ini akan membahas: (1) bentuk penanda fatis yang terdapat dalam BJ yang digunakan oleh masyarakat Madura di Jember, (2) distribusi penanda fatis pada kalimat yang terdapat dalam BJ yang digunakan oleh masyarakat Madura di Jember.

\section{Metode Penelitian}

Langkah-langkah yang dilakukan dalam penelitian ini adalah: (1) penentuan lokasi penelitian, (2) pemerolehan sumber data dan data, (3) tahap penyediaan data, (4) analisis data, dan (5) pemaparan hasil analisis data.

Penelitian ini dilaksanakan di Jalan Trunojoyo, Kecamatan Kaliwates, Kabupaten Jember. Pemilihan Jalan Trunojoyo, Kecamatan Kaliwates sebagai lokasi penelitian karena letaknya yang berada di pusat kota dan mayoritas masyarakatnya merupakan penutur BM. Kemudian dalam interaksinya, penutur BM sering menggunakan BJ. BJ yang digunakan oleh penutur Madura tersebut mengalami perubahan. Perubahan bahasa yang dialami penutur Madura ketika berbicara dalam BJ disebabkan oleh pengaruh bahasa pertamanya, yaitu BM.

Sesuai dengan rumusan masalah, objek penelitian ini adalah penanda fatis. Data penelitian ini berupa data kalimat yang di dalamnya terdapat bentuk penanda fatis. Data yang diperoleh dalam penelitian ini kemudian ditranskripsi dan diklasifikasi. Datanyaberupa transkip percakapan yang di dalamnya terdapat penanda fatis berupa bentukdan distribusiberdasarkan konteks yang menyertai. Data yang telah disusun kemudian diklasifikasikan berdasarkan jenisnya. 
Sumber data penelitian ini adalah masyarakat Madura yang tinggal di Jember. Penelitian ini membutuhkan beberapa informan sebagai narasumber dalam pengumpulan data. Informan dalam penelitian ini dibedakan menjadi tiga, yaitu informan utama, informan tambahan, dan informan pangkal. Informan utama menurut Sofyan (2009:27) adalah informan yang secara intensif diajak berdialog atau diwawancarai serta diminta untuk mengungkapkan penggunaan penanda fatis dalam BJ yang digunakan oleh masyarakat Madura di Jember, baik dalam bentuk kata maupun kalimat. Informan utama dalam penelitian ini sebanyak lima orang yang dipilih secara purposif, yakni masyarakat asli Jember yang bermukim di Jalan Trunojoyo Kecamatan Kaliwates, Kabupaten Jember. Informan utama yang digunakan dalam penelitian ini harus memenuhi beberapa kriteria 1) lahir dan besar di Jember, 2) sehat jasmani dan rohani, 3) mempunyai alat ucap normal, 4) etnik Madura yang dalam komunikasinya menggunakan BM dan BJ, dan 5) pembatasan usia yaitu antara 25-60 tahun. Informan tambahan adalah seluruh penutur BM yang dalam komunikasinya menggunakan BJ baik yang berada di Jalan Trunojoyo Kecamatan Kaliwates maupun di seluruh wilayah Jember. Informan pangkal adalah para praktisi dan pemerhati BJ dan BM yang lahir dan tinggal di wilayah Jember. Informan ini di samping dimintai informasinya yang berkenaan dengan unsur-unsur penanda fatis dalam BJ yang digunakan oleh masyarakat Madura di Jember, juga dijadikan sebagai mitra diskusi untuk memecahkan permasahan di bidang penanda fatis dalam BJ yang digunakan masyarakat Madura di Jember yang problematis dan tidak dapat dipecahkan oleh peneliti dalam melakukan analisis data.

Metode yang digunakan dalam pengumpulan data yaitu metode simak atau penyimakan. Dalam melakukan penyimakan terhadap tuturan, peneliti menggunakan cara atau teknik yang terbagi dalam teknik dasar dan teknik lanjutan. Teknik dasar metode simak adalah teknik sadap. Teknik lanjutan metode simak adalah teknik Simak Libat Cakap (SLC) dan teknik Simak Bebas Libat Cakap (SBLC). Teknik SLC adalah kegiatan menyadap tuturan sambil berpartisipasi dalam dialog, artinya peneliti terlibat langsung dalam dialog. Teknik SBLC adalah kegiatan menyadap atau menyimak yang dilakukan tanpa berpartisipasi dalam dialog, artinya peneliti hanya sebagai penyimak tuturan (Sudaryanto, 1993:133-134). Dalam penelitian ini digunakan teknik SLC dan SBLC.

Metode yang digunakan dalam analisis data adalah metode agih. Metode agih digunakan untuk mengetahui bentuk dan distribusi penanda fatis. Metode agih yaitu metode dengan alat penentunya bagian dari bahasa yang bersangkutan itu sendiri (Sudaryanto,1993: 15). Teknik dasar yang digunakan dalam metode agih dalam penelitian ini adalah teknik Bagi Unsur Langsung (BUL) dan teknik lesap. Data yang sudah diperoleh, kemudian dipilah sesuai dengan teori bentuk dan distribusi penanda fatis. Teknik lesap digunakan untuk menjelaskan bentuk penanda fatis dan untuk mengetahui seberapa penting kedudukan penanda fatis dalam suatu kalimat.

Penyajian hasil analisis data pada penelitian ini menggunakan metode informal. Metode informal yaitu penyajian hasil analisis data yang berupa perumusan dengan kata-kata biasa walaupun dengan terminologi yang sifatnya teknis (Sudaryanto, 1993:145). Penyajian hasil analisis data dalam penelitian ini menggunakan transkripsi fonetis dan ortografis: EYD bahasa Indonesia, ejaan bahasa Madura, dan ejaan bahasa Jawa.

\section{Hasil dan Pembahasan}




\subsection{Bentuk Penanda Fatis}

Bentuk penanda fatis dalam BJ yang digunakan masyarakat Madura di Jember berupa 1) partikel, 2) kata fatis, 3) pengulangan kata, dan 4) penggunaan afiks. Keempat bentuk penanda fatis tersebut adalah sebagai berikut.

\subsubsection{Partikel}

Berikut ini bentuk-bentuk partikel fatis dalam BJ yang digunakan masyarakat Madura di Jember. Bentuk-bentuk partikel fatis dalam BJ yang digunakan masyarakat Madura di Jember tersebut adalah jhâ', kan, ko dan ra, yâ, lâ, pas, ta, dhing, ki, lah, dan mbok. Bentukbentuk partikel fatis tersebut dapat diuraikan pada data berikut.
A. Partikel jhâ'
1)“Jhấ' Dika mas mau ndak gelem mbalèkno"
[jhə? Dika mas mau nḍa? gələm mbale?no]
'(gara-gara) Dika tadi tidak mau mengembalikan, Mas'.

Bentuk partikel $j h \hat{a}$ ' biasanya diikuti oleh partikel la dan wong seperti data berikut.

2) "Jhấ la Yati sekarepan".

[jhə? la yati səkarəpan]

'(Namanya) juga Yati ya asal-asalan'.

3) “Iyo, aku turuné bengijhâ' wong aku mau awan ngombé kopi akeh"

[iyə aku turune bəyi jhə? wəy akumau awan yombe kəpi akeh]

'Iya,aku tidurnya malam (soalnya) aku tadi siang minum banyak kopi'

B. Partikel kan

4) "Kan aku wés ngomong tutupen mau"

[kan aku wes yomon tutupən mau]

"Aku kan sudah bicara tutupkan tadi"

Partikel kan mempunyai variasi tuturan yakni rak, seperti pada data berikut.

5) "Rak Lék Paidi séng mbayari kabèh".

[ra? le? paidi sey mbayari kabeh]

'KanLek Paidi yang membayari semua'.

C. Partikel ko dan $r a$

6) "Iyo ko, ngentèni ibuk duwé dhuwék"

[iyo ko yənteni ibu? duwe ḍuwe?]

'Iya (kan sudah aku bilangi) nunggu ibu punya uang!'

7) "Meneng $\underline{r a}$ ! Karepku"

[mənəџ ra karəpku]

'Diam (aku bilang diam), terserah aku!'

Bentuk partikel $r a$ biasanya diikuti oleh partikel $k a h$, $p a$, dan kata wes, seperti pada data berikut.

8) "Iyo ra kah karepmu, Mad!"

[iys ra kah karəpmu mat] 
'Iya (sudah) terserah kamu, Mad!'

9) "Ndak ra pa, aku ndak katé mindo gawé"

[nḍa? ra pa aku nḍak kate minḍo gawe]

'Tidak (aku benar-benar tidak mau) aku tidak mau kerja dua kali

10) “Iyo ra wés", Yu Tun".

[iyo ra wes yu tUn]

'Iya (terserah sudah) Yu Tun.'

Partikel ko dan ra mempunyai variasi tuturan yakni kok, kah, dan yok, seperti pada data berikut.

11) "Diwara lombokkok!"

[diwara lombo? ks?]

"Dibilang cabai, kok!"

12) “ Ojo yu-mlayu kah!”

[ojo yu mlayu kah]

'(sudah dibilang) Jangan lari-lari saja!'

13) “Jarno yok karepé arèke!"

[jarn॰ yə? karəpe are?e]

'Biarkan (sudah dibilangi) apa kata anaknya!'

D. Partikel $y \hat{a}$

14) "Ojo meler yâ, Nak!"

[əjo? mələr yə na?]

'Jangan nakal ya nak!'

Partikel yâ mempunyai variasi tuturan yakni yo, seperti pada data berikut.

15) “Arep opo ndak yo arékè?"

[arəp эpo nḍa? yə are?e]

'Mau apa tidak ya anaknya?'

E. Partikel lâ

16) "Lâ, wingi sék selawé, saiki wés pitu likur, kebacut!"

[lə wini se? səlawe sa?iki wes pitu likUr kəbacUt]

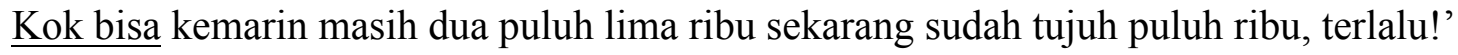

Partikel lâ biasanya diikuti oleh partikel kan, seperti pada data berikut.

17) "lâ kanséng loro nemen séng wèdok"

[lə kan séy loro nəmən séy wedっ?]

Lho kan yang sakit parah istrinya" 
Partikel lâ mempunyai variasi tuturan yakni lho dan $l$ ha, seperti pada data berikut.

18) "Lhokoen katé nang Bali késok?"

[lho koən kate nay bali keso?]

'Lho kamu mau ke Bali besok?'

Bentuk partikel lho biasanya sering diikuti dengan kata $m a$ ', partikel kan dan kok, seperti data berikut.

19) "Lho mak digawé jedhingan yo suwi, nggawé timbo aé wés akèh utangé masjid iki!"

[lho ma? digawe joḍinan yo suwi ngawe timbo ae wes akch utaje masjid iki] 'Lho kokdibuat bak mandi ya lama. Buat timba saja sudah banyak hutangnya masjid ini'.

20) "Lho kan wés tak kandani"

[lho kan wes ta? kandiani]

'Tho kan sudah saya bilangi'

21) "Lho kokkelambi biru? saiki kelambi batik ijo".

[lho ko? klambi biru sa?iki klambi bațI? ijo]

'Lho kok baju biru? Sekarang baju batik hijau'.

22) “Lha pantesan mau mlakuné Kang Min lon-alon”.

[lha pantəsan mau mlakune kay min lon alon]

'Ya pantesan tadi jalannya Kang Min pelan-pelan'.

Bentuk partikel lha biasanya diikuti dengan partikel kok, kan dan kata wong, seperti data berikut.

23) "Lha kokdadi aku, koen aé ndak kiro is"

[lha ko? dadi aku, koən ae nḍa? kiro iso]

'Lho kok aku, kamu saja tidak mungkin bisa'.

24) "Iha kan maine saiki"

[lha kan maIne sa?iki]

(benar) kan mainnya sekarang"

25) "Pantesan Mbak Nisa pindah, lha wong mertuané nyocot sara".

[pantəsan mba? nisa pinḍah lha woy mərtuwane ňocot sara]

'Pantesan Mbak Nisa pindah, (orang) mertuanya cerewet sekali'.

F. Partikel pas

26) "Yaopo pas ndak sido ta?"

[ya? opo pas nḍa? sido ta?

'Lalu (bagaimana) apa tidak jadi?' 
G. Partikel $t a$

27) "Sabar ta Bék, séng sabar!"

[sabar ta be? sey sabar]

'(yang) sabar Bek yang sabar!'

Bentuk partikel ta biasanya diikuti oleh partikel la, seperti data berikut.

28) "Ojo Van, ojo nakal-nakal ta la dadi arèk iku!"

[ojo van ojo nakal nakal ta la dadi are? iku]

'Jangan Van, jangan nakal-nakal jadi anak itu!'

H. Partikel dhing

29) "Iyo dhing lali".

[iyo ḍIn lali]

'(oh iya, ya) lupa'.

I. Partikel $k i$

30) "Dhudhuk ki, dhudhuk aku séng mangan".

[dudu? ki dudu? aku sen manan]

'Bukan (tuh), bukan aku yang makan

J. Partikel lah

31) "Iyolah, aku séng nggawé".

[iyslah aku sey ngawe]

'(ya, iyalah) aku yang buat'

K. Bentuk Partikel mbok

32) "Mbok ojosak munu regané, korting titik!"

[mbə? ojo? sa? munu rəganə kortin titi?]

'(Ya) jangan segitu harganya, didiskon sedikit!'

Partikel mbok biasanya diiktui oleh kata yo, seperti pada data berikut.

33) "Mbok yoistirahat, jo ku-mlaku tok!"

[mbo? yo istirahat jo? ku mlaku to?

'(seharusnya ya) istirahat, jangan jalan-jalan terus!'

34) "Kari buluk sepèdahé, mbok yâ dikumbah!"

[kari buluk səpeḍae mbə? yə dikumbah]

'Kotor sekali sepedahnya, (seharusnya ya) dicuci!'

\subsubsection{Kata Fatis}

Berikut ini bentuk-bentuk kata fatis dalam BJ yang digunakan masyarakat Madura di Jember yang diucapkan oleh masyarakat Jember dalam peristiwa tutur. Bentuk-bentuk kata fatis dalam BJ yang digunakan masyarakat Madura di Jember tersebut adalah sènga', ma', 
adâ', bâh, mara, jeneng, mboh, wés, dan mayo'. Bentuk-bentuk kata fatis tersebut adalah sebagai berikut.

A. Kata sènga'

35) "Sènga'nèk lèwat èmbong gedhe yo, Fat".

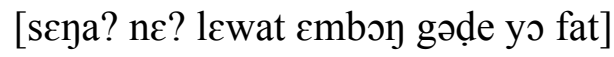

'(hati-hati) kalao lewat jalan raya ya, Fat!'

Kata fatis sènga' mempunyai variasi tuturan yakni awas, seperti pada data berikut.

36) "Awaslèk nyabrang yo, Nduk!"

[awas le? ňabray yo nḍU?]

'(hati-hati) kalau menyabrangi jalan, $N d u k !$ '

B. Kata $m a$ '

(37) “Bawangé ma' dicampurno mbék berambang? angèl engkok nèk njupuk”.

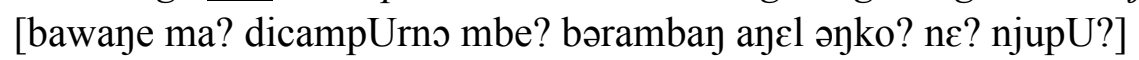

'Bawang putihnya kok dicampurkan sama bawang merah? Sulit nanti kalau mengambil'

Bentuk kata fatis $m a$ ' mempunyai variasi tuturan yakni kok, seperti pada data berikut.

(38) "Kok aku ditaningiberambang?

[ko? aku ditanini bramban]

"Kok, aku diberi bawang merah?"

C. Kata adâ'

(39) “Adâ' koen keliru”.

[ạ̣ə? koən kəliru]

'(kapok) kamu keliru'.

Bentuk kata adâ' biasanya diikuti dengan partikel la dan kata wés, seperti data berikut.

(40) “Adâ' la kasèp, wés jam songo".

[adə? la kasep wes jam sono]

(ya payah) terlambat, sudah jam sembilan'.

(41) 'Yu Jul wingi nané ngomongé keceplosan, adâ' wés kenék srangap mbék panitiané".

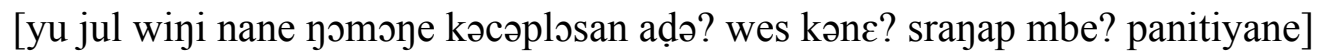

' $Y u$ Jul kemarin lusa bicara keceplosan, (ya pantesan) kena omeli sama panitianya'.

D. Kata bâh

(42) "Bâh dadiné kok biru, rèk?"

[bəh dadine ko? biru re?]

'Wah jadinya kok biru, rek?' 
Bentuk kata fatis bâh sering diikuti oleh kata $m a$ ' dan partikel kok, seperti data berikut.

(43) "Bâh ma' tuku séng biru? abang iku lebih apik".

[bəh ma? tuku sey biru aban iku ləbIh api?]

'Lho kok beli yang biru? Merah lebih bagus'.

(44) "Bâh kok sekolah nang madrasah? mangkané nyabrang èmbong bahaya". [bəh ko? səkılah nay madrasah maykane ňabray embon bahaya] 'Lho kok sekolah di madrasah? Mangkanya lewat jalan raya, bahaya'.

E. Kata mara

(45) "Diwara entèk wongé, lèk ndak percoyo mrono'o, mara!"

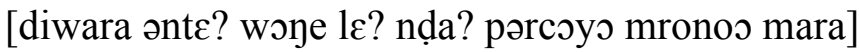
'Dibilangi sudah tidak ada orang, kalau tidak percaya ke sana saja!'

Bentuk kat fatis mara mempunyai variasi tuturan yakni agé, seperti pada data berikut.

(46) “Wés mari tetep ndak kenèk, kéné jajalen agé!"”

[wes mari tətəp nḍa? kənع? kene jajalən age]

'Sudah selesai tetap tidak bisa, (ayo) sini kamu coba!'

F. Bentuk Kata Fatis jeneng

(47) "Jeneng Dimas mé-ramé tok mulai mau".

[jənəy dimas me rame țo? mulai mau]

'(salahnya) Dimas ramai terus mulai tadi'

Bentuk kata fatis jeneng mempunyai variasi tuturan yakni wong, seperti pada data berikut.

(48) “Wong Jokowi prèsidèné".

[woy jokıwi presiḍcne]

'(Orang) Jokowi presidene (memang tidak bisa jadi presiden)'

G. Kata $m b o h$

(49) "Yo mboh koen". [yo mboh koən]

'Ya (terserah) kamu'.

Bentuk kata fatis mboh biasanya diikuti oleh kata wes, partikel la, partikel kok, seperti pada data berikut.

(50) "Mboh wes, aku pasrah saiki."

[mboh wes aku pasrah sa?iki]

'(terserahlah), aku pasrah sekarang'.

(51) "Iyo mundak barang, $\underline{\text { mboh la }}$.

[iys munḍa? baray mboh lah] 
'Iya naik segala, (tidak tahu sudah)

(52) "Mboh kok, aku iki manut opo jaré bapak".

[mboh ks? aku iki manUt spo jare bapa?]

(saya kan sudah bilang), saya ini nurut apa kata bapak'.

H. Kata wés

(53) "Iyo wéskarepmu, pokoé aku lèh-olèhno".

[iyo wes karəpmu poko?e aku lch olchno]

'Iya sudah terserah pokoknya aku bawakan oleh-oleh'.

Bentuk kata fatis wés biasanya diikuti oleh partikel $t a$, la, dan $r a$, seperti data berikut.

(54) "Wés ta ojo cerèmèh!"

[wes ta ojo cəremeh]

'Sudah ya jangan bawel!'

(55) “Wés laopo jarèku, koen ndak usah lok-mèlok!"

[wes la opo jareku, koən nḍa? usah lø? mel๖?]

'Sudahlah percayakan padaku, kamu tidak usah ikut-ikut'.

(56) “Wés rakoen neng-meneng ngunu!

[wes ra kəən nəy mənəy yunu]

'(sudah aku bilang) kamu diam!'

I. Bentuk Kata Fatis mayo'

(57) "Mayo' budal, cepetan!"

[mayo? budal cəpətan]

'(ayo) berangkat, cepat!

Kata fatis mayo' mempunyai variasi tuturan yakni ayo', seperti pada data berikut.

(58) “Ayo' turuo!"

[ayo? turuwo]

'(cepatlah) tidur!'

\subsubsection{Pengulangan Kata}

Berikut ini bentuk-bentuk pengulangan kata fatis dalam BJ yang digunakan masyarakat Madura di Jember yang diucapkan oleh masyarakat Jember dalam peristiwa tutur. Bentuk-bentuk pengulangan kata fatis dalam BJ yang digunakan masyarakat Madura di Jember adalah cén, ndak, jal, mboh, yo, dan iku. Bentuk-bentuk pengulangan kata fatis tersebut adalah sebagai berikut.

(59) “Cén iyo cén, ngopo'o?”

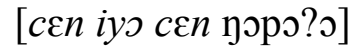

'(memang) iya (memang), kenapa?'

(60) "Ndak kiro ndak tenang aé". 
[nḍa? kiro nụa? tənay ae]

'Tidak mungkin (tidak mungkin terjadi) tenang saja'.

(61) “Jal koen jal séng ngomong déwé!"

[jal kəən jal sey yomøy dewe]

'Coba kamu yang bicara sendiri (biar kamu merasakan)!'

(62) "Mboh wes mboh aku kesel".

[mboh wes mboh aku kəsəl]

'Aku tidak tahu (sungguh aku tidak tahu) aku capek'

(63) "Iyo yo aku séng nyetir"

[iyə yə aku sen ňətIr]

'Iya (iya) aku yang menyetir'

(64) “Iku ku séng nyolong”

[iku ku sey ňolon]

'Itu lho yang mencuri'

\subsubsection{Penggunaan Afiks}

Berikut ini bentuk-bentuk penggunaan afiks fatis dalam BJ yang digunakan masyarakat Madura di Jember yang diucapkan oleh masyarakat Jember dalam peristiwa tutur. Bentuk-bentuk penggunaan afiks fatis dalam BJ yang digunakan masyarakat Madura di Jember adalah - an dan - en. Bentuk-bentuk penanda fatis berupa penggunaan afiks tersebut adalah sebagai berikut.

(65) "Cepetan mlayu!"

[copətan mlayu]

'cepatlah lari!'

(66) "Gowoen klambiné kabèh!"

[gəwəən klambine kabeh]

'Bawalah semua bajunya'

\subsection{Distribusi Penanda Fatis pada Kalimat}

Distribusi penanda fatis yang berupa partikel, kata fatis, pengulangan kata fatis, dan penggunaan afiks dalam BJ yang digunakan masyarakat Madura di Jember pada kalimat dapat terletak di (1) awal, (2) tengah, (3) awal dan tengah, (4) tengah dan akhir, (5) awal, tengah, dan akhir.

\subsubsection{Distribusi Partikel}

Distribusi partikel dalam BJ yang digunakan masyarakat Madura di Jember pada kalimat dapat terletak di 1) awal, 2) tengah, 3) awal dan tengah, 4) tengah dan akhir, 5) awal, tengah, dan akhir kalimat. 
A. Partikel yang Terletak di Awal

Partikel yang terletak di awal pada kalimat di antaranya adalah partikel la, lha, tho ma',lho kan dan lho kok.

B. Partikel yang Terletak di Tengah

Partikel yang terletak di tengah pada kalimat di antaranya adalah partikel lah. Partikel lah dapat berdistribusi di tengah kalimat deklaratif.

C. Partikel yang Terletak di Awal dan Tengah

Partikel yang terletak di awal dan tengah pada kalimat di antaranya adalah partikel jhâ', jhâ' la, dan jhâ' wong, la kan, lha kok, lha kan dan lha wong, lho, mbok (mbok yo, mbok yâ), rak, dan yâ.

D. Partikel yang Terletak di Tengah dan Akhir

Partikel yang terletak di tengah dan akhir pada kalimat di antaranya adalah partikel dhing, kah, ko, ki, ra (ra kah, ra pa, ra wés), ta (ta la), dan yok.

Ee. Partikel yang Terletak di Awal, Tengah, dan di Akhir

Partikel yang terletak di awal, tengah, dan di akhir kalimat di antaranya adalah partikel kan, kok, pas, dan yo.

\subsubsection{Distribusi Kata Fatis dalam Bahasa Jawa Dialek Jember}

Distribusi kata fatis dalam BJDJ pada kalimat dapat terletak di (1) awal, (2) awal dan tengah, (3) tengah, dan (4) awal dan akhir.

A. Kata Fatis yang Terletak di Awal

Kata fatis yang terletak di awal pada kalimat di antaranya adalah partikel awas, sènga',bâh (bâh ma', bâh kok), mayo', ayo', wes ta dan wes la, wong, dan jeneng.

B. Kata Fatis yang Terletak di Awal dan Tengah

Kata fatis yang terletak di awal dan tengah kalimat di antaranya adalah partikel adâ (adâ' la, adâ' wés), dan ma'.

C. Kata Fatis yang Terletak di Tengah

Kata fatis yang terletak di tengah kalimat di antaranya adalah kata mboh dan wés.

D. Kata Fatis yang di Awal dan Akhir

Kata fatis yang terletak di awal dan akhir kalimat di antaranya adalah kata mara dan agé, mboh wés, mboh la, dan mboh kok.

\subsubsection{Distribusi Pengulangan Kata}

Distribusi penanda fatis berupa pengulangan kata cén, ndak, jal, mboh, yo, dan iku dalam BJ yang digunakan masyarakat Madura di Jember pada kalimat dapat terletak ditengah kalimat introgatif, deklataif, dan kalimat imperatif.

\subsubsection{Distribusi Penggunaan Afiks}

Distribusi penanda fatis berupa penggunaan afiks -an dan -en dalam BJDJ pada kalimat dapat melekat di akhir kata kerja dan pada kalimat imperatif.

\section{Kesimpulan}

Berdasarkan hasil penelitian dan pembahasan masalah yang telah diuraikan, dapat diambil kesimpulan bahwa bentukdandistribusi dalam BJ yang digunakan masyarakat Madura di Jember sangat beragam. Dilihat dari segi penuturnya, bentuk penanda fatis dalam BJ yang 
digunakan oleh masyarakat Madura di Jember bermacam-macam serta dari segi pemakaian dan distribusinya juga bervariasi.

Bentuk penanda fatis dalam BJ yang digunakan oleh masyarakat Madura di Jember, berupa 1) partikel, 2) kata fatis, 3) pengulangan kata, dan 4) penggunaan afiks. Penanda fatis yang berupa partikel, yaitu jhâ', kan, ko dan ra, yâ, lâ, pas, ta, dhing, ki, lah, dan mbok. Penanda fatis yang berupa kata fatis, yaitu sènga', ma', adâ', bâh, mara, jeneng, mboh, wés, dan mayo'. Penanda fatis yang berupa pengulangan kata, yaitu cén, ndak, jal, mboh, yo, dan $i k u$. Penanda fatis berupa penggunaan afiks, yaitu - an dan -en.

Distribusi penanda fatis yang berupa partikel dalam bahasa Jawa dialek Jember dapat terletak 1) awal, 2) tengah, 3) awal dan tengah, 4) tengah dan akhir, 5) awal, tengah, dan akhir kalimat. Distribusi penanda fatis yang berupa kata fatis dapat terletak di 1) awal, 2) awal dan tengah, 3) tengah, dan 4) awal dan akhir kalimat. Distribusi penanda fatis yang berupa pengulangan kata dapat terletak di tengah kalimat. Distribusi penanda fatis yang berupa penggunaan afiks dapat melekat pada akhir kata kerja.

\section{Daftar Pustaka}

Kridalaksana, Harimurti. 2005. Kelas Kata dalam Bahasa Indonesia. Jakarta: Gramedia Pustaka Utama.

Pawitra, Adrian. 2009. Kamus Lengkap Bahasa Madura Indonesia. Jakarta: PT Dian Rakyat.

Sofyan, Akhmad dan Bambang Wibisono. 2001. "Latar Belakang Psikologis Pemilihan Bahasa pada Masyarakat Multilingual (Studi Kasus Pemakaian Bahasa oleh Masyarakat Etnik Madura di Jember)", dalam Jurnal Ilmu-Ilmu Humaniora. Vol. 2/ No. I Januari, Fakultas Sastra Universitas Jember.

Sofyan, Akhmad. 2009. "Morfologi Bahasa Madura Dialek Sumenep.” Tidak Diterbitkan. Disertasi. Yogyakarta: Fakultas Ilmu Budaya Universitas Gadjah Mada.

Sudarmanto. 2011. Kamus Lengkap Bahasa Jawa. Semarang: Widya Karya.

Sudaryanto. 1993. Metode dan Aneka Teknik Analisis Bahasa Pengantar Penelitian Wahana Kebudayaan secara Linguistik. Yogyakarta: Duta Wacana University Press. 